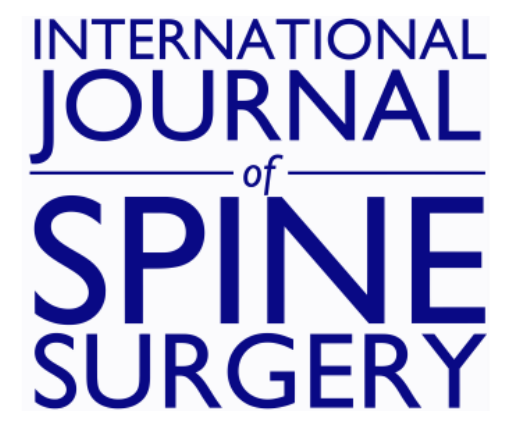

\title{
Fluoroscopy-guided pedicle screw accuracy with a mini-open approach: a tomographic evaluation of 470 screws in 125 patients
}

José Antonio Soriano-Sánchez, Luis Alberto Ortega-Porcayo, Carlos Francisco Gutiérrez-Partida, Luis Rodolfo Ramírez-Barrios, Ramses Uriel Ortíz-Leyva, Manuel Rodríguez-García and Oscar Sánchez-Escandón

Int J Spine Surg 2015, 9 ()

doi: https://doi.org/10.14444/2054

http://ijssurgery.com/content/9/54

This information is current as of April 26, 2023.

Email Alerts Receive free email-alerts when new articles cite this article. Sign up at: http://ijssurgery.com/alerts

The International Journal of Soing Surgerhthttp://ijssurgery.com/ by guest on April 26, 2397 Waterbury Circle, Suite 1, 


\section{Fluoroscopy-guided pedicle screw accuracy with a mini-open approach: a tomographic evaluation of 470 screws in 125 patients}

José Antonio Soriano-Sánchez, MD,1 Luis Alberto Ortega-Porcayo, MD,1,2 Carlos Francisco Gutiérrez-Partida, MD,1 Luis Rodolfo Ramírez-Barrios, $M D,{ }^{1}$ Ramses Uriel Ortíz-Leyva, MD, ${ }^{1}$ Manuel Rodríguez-García, MD, ${ }^{1}$ Oscar Sánchez-Escandón, $M D^{1}$

1 Neurological Center, American British Cowdray Medical Center, Mexico City, Mexico, 2 Department of Neurosurgery, National Institute of Neurology and Neurosurgery "Manuel Velasco Suárez," Mexico City, Mexico.

\section{Abstract}

Background

Transpedicular screws are currently placed with open free hand and minimally invasive techniques assisted with either fluoroscopy or navigation. Screw placement accuracy had been investigated with several methods reaching accuracy rates from $71.9 \%$ to $98.8 \%$. The objective of this study was to assess the accuracy and safety for 2-D fluoroscopy-guided screw placement assisted with electrophysiological monitoring and the inter-observer agreement for the breach classification.

\section{Methods}

A retrospective review was performed on 125 consecutive patients who underwent minimally invasive transforaminal lumbar interbody fusion and transpedicular screws placement between the levels of T-12 and S- 1 . Screw accuracy was evaluated using a postoperative computed tomography by three independent observers. Pedicle breach was documented when there was a violation in any direction of the pedicle. Inter-observer agreement was assessed with the Kappa coefficient.

Results

A total of 470 transpedicular screws were evaluated between the levels of T-12 and S-1. In 57 patients the instrumentation was bilateral and in 68 unilateral. A substantial degree of agreement was found between the observers A$B(\kappa=0.769)$ and A-C $(\kappa=0.784)$ and almost perfect agreement between observers B-C $(\kappa=0.928)$. There were a total of 427.33 (90.92\%) screws without breach, 39.33 (8.37\%) minor breach pedicles and 3.33 (0.71\%) major breach pedicles. The pedicle breach rate was $9.08 \%$ Trajectory pedicle breach percentages were as follows: minor medial pedicle breach $4.68 \%$, minor lateral pedicle breach $3.47 \%$, minor inferior pedicle breach $0.22 \%$, and major medial breach $0.70 \%$. No intraoperative instrumentation-related or postoperative clinical complications were encountered and no surgical revision was needed.

\section{Conclusions}

Our study demonstrated a high accuracy (90.2\%) for 2-D fluoroscopy-guided pedicle screw using electromonitoring. Only $0.71 \%$ of the 470 screws had a major breach. Knowing the radiological spine pedicle anatomy and the correct interpretation of EMG are the key factors for this technique.

KEYWORDS: ACCURACY, COMPUTED TOMOGRAPHY, ELECTROMONITORING, FLUOROSCOPY, MINIMALLY INVASIVE, MINI-OPEN, PEDICLE SCREW. VOLUME 9 ARTICLE 54 DOI: 10.14444/2054

\section{Introduction}

Application of transpedicular screws for spinal instability had undergone technique refinements pursuing 100\% accuracy. Techniques can be classified as open free-hand and minimally invasive assisted with either fluoroscopy or navigation. ${ }^{1}$ Pedicle screw fixation is a well-known and safe technique for spine surgeons with a low rate of complications. ${ }^{2}$ However, risk of serious neurological lesions, ${ }^{3}$ cerebrospinal fluid leaks, ${ }^{4}$ $\operatorname{vascular}^{5,6}$ and visceral injures ${ }^{7}$ have raised interest to evaluate safety and accuracy for pedicle screw placement. 
The objective of this study was to asses the accuracy and safety for 2-D fluoroscopy guided pedicle screw placement assisted with electrophysiological monitoring through a mini-open approach used for minimally invasive spine surgery transforaminal lumbar interbody fusion (MISS-TLIF).

\section{Materials and Methods}

A retrospective imagenological review was performed on 125 consecutive patients who underwent MISS TLIF and transpedicular screw placement between the levels of T-12 and S-1 by a single neurosurgeon (JASS), during a period between January 2010 to November 2014 at the ABC Medical Center in Mexico City, Mexico. The Education and Research Department of the --ABC Medical Center-- approved this study.

All patients were treated electively of 1, 2 or 3 levels using a minimally invasive transforaminal lumbar interbody fusion for the treatment of degenerative disk disease and spondylolisthesis of the lumbar spine. First time and revision cases were included in the study. Clinical follow up and postoperative computed tomography (CT) were available and reviewed for the 125 patients. CT (Brilliance 64, Phillips) images were assessed using "bone window" in the axial, coronal and sagittal planes by three independent observers, all of them neurosurgeons. Pedicle breach was documented when there was a violation in any direction of the pedicle as previously reported by Smith et al. ${ }^{8}$ and was classified in three grades: 1) No breach. 2) Minor breach, when the breach was $\leq 2$ $\mathrm{mm} .3)$ Major breach, when the pedicle violation was $\geq 3 \mathrm{~mm}$ (Figure 1).

\section{Operative technique}

All of the cases were performed under general anes-
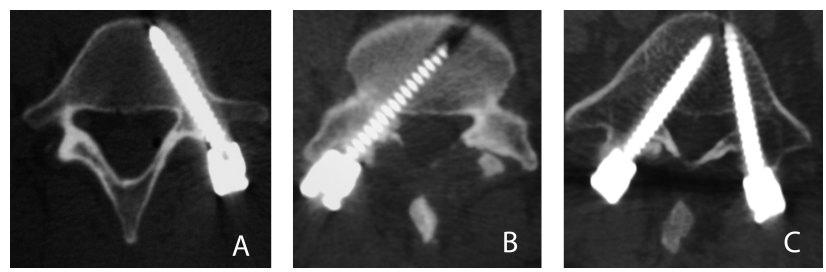

Fig. 1. Postoperative axial CT image depicting the classification used for accuracy assessment. A. No breach. B. Minor breach $\leq 2 \mathrm{~mm}$. C. Major breach $\geq 3 \mathrm{~mm}$ thesia using a radiolucent operating table, a 2-D Carm fluoroscope, electromyography (EMG), somatosensory evoked potentials, and motor evoked potentials. Following intubation, patient was placed in prone position; the lumbar spine was prepared and draped in sterile fashion. We used a $2 \mathrm{~cm}$ incision that was $1.5 \mathrm{~cm}$ lateral to the ipsilateral pedicle marked by AP fluoroscopy. Monopolar dissection was made through the subcutaneous tissue. The thoraco-lumbar fascia and muscle erector spinae fascia was opened and the plane between the iliocostalis and the longissimus muscles was identified. A 16 to $18 \mathrm{~mm}$ tubular retractor (METRx System, Medtronic) was inserted in between the muscles by dilating over a precisely placed guide tube over the facet joint. The facet complex was drilled out with a straight high-speed match head cutting drill. Discectomy and MISS-TLIF were performed using Peek cages (JULIET OL, Spineart) filled with demineralized bone matrix. Following decompression and interbody fusion, fluoroscopic guided pedicle screws were placed using the true AP and lateral views technique. Jamshidi needle was introduced with the true AP view at the most lateral part of the elliptical pedicle (Figure 2A); the needle was introduced until the medial border of the pedicle was reached (Figure 2B). Fluoroscopic lateral view was obtained to confirm that the tip of the needle was beyond the pedicle, anterior to the spinal canal (Figure $2 \mathrm{C}$ ). The Jamshidi needle was introduced deep into the vertebral body. The guide wire was introduced inside the Jamshidi needle (Figure 2D), the path was prepared with the tap and finally the screw was placed confirming the final position with lateral and AP views (Figure 2E, Figure 2F). Jamshidi needle and screws were introduced using a stimulation threshold according to previous stimulation series reported in the literature. ${ }^{9.11}$ In case of occurrence of root irritation related to the insult of the medial wall of the pedicle, the surgeon was alerted. A stimulus intensity of 7 $\mathrm{mA}$ was applied to the top during the introduction of the Jamshidi needle. This stimulus was increased to $15 \mathrm{~mA}$ while placing the screws. If there was any response to stimulation during surgery, screw was moved over and placed in a different position and trajectory. The rod was secured through the same incision. When contralateral fixation was needed; the screws were placed using a mini-open contralateral 
approach

\section{Statistical Analysis}

Statistic analysis was performed with IBM SPSS Statistics Software version 20.0. The accuracy was examined according to the spinal levels that were treated. Pedicle breach rates were analyzed in terms of occurrence and as the degree of breach: no breach, minor $(\leq 2 \mathrm{~mm})$ or major $(\geq 3 \mathrm{~mm})$ breach. Kappa coefficient was calculated for testing inter-observer agreement. Kappa coefficients were interpreted as follows: Almost perfect agreement $>0.81$, substantial agreement 0.61-0.80, moderate agreement 0.41-0.60, fair agreement 0.21-0.40 and slight agreement $0.01-0.20 .^{12}$

\section{Results}

In 125 patients, a total of 470 transpedicular screws were assessed between the levels of T-12 and S-1. Clinical follow up and postoperative CT were performed to all the patients. In 57 patients the instrumentation was bilateral and in 68 unilateral. Kappa analysis was performed to ascertain the degree of agreement for screw accuracy classification (No breach/Minor breach $\leq 2 \mathrm{~mm} /$ Major breach $\geq 3 \mathrm{~mm}$ ) between the three observers. A substantial degree of agreement was found between the observers A-B $(\kappa=0.769)$ and $A-C(\kappa=0.784)$ and almost perfect agreement between observers B-C $(\kappa=0.928)$. Table 1 shows the breached pedicle results, screws and percentages are expressed as the mean of the three observers.

There were a total of 427.33 (90.92\%) screws without

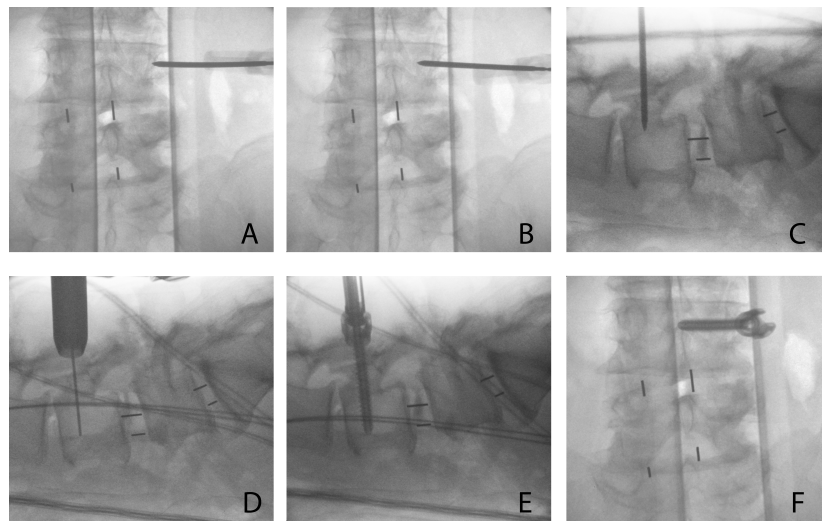

Fig. 2. Fluoroscopic-guided screw placement technique using the true AP and lateral views. breach, 39.33 (8.37\%) minor breached pedicles and $3.33(0.71 \%)$ major breached pedicles (Figure 1); of the 125 patients, 31 patients $(26.4 \%)$ had a pedicle breach. The incidence of pedicle breach per level using observer C (Figure 3) results was as follows: L-2 0/9 (0\%), L-3 6/29 (20.68\%), L-4 18/125 (14.4\%), L-5 13/178 (7.30\%), S-1 7/124 (5.64\%). There was one screw in L-1 with a minor medial breach; the other two cases at T-12 and L-1 did not have any breach. Trajectory pedicle breach percentages were as follows: minor medial pedicle breach $4.68 \%$, minor lateral pedicle breach $3.47 \%$, minor inferior pedicle breach $0.22 \%$, and major medial breach $0.70 \%$. There were only three major medial pedicle breaches for two observers (L-5 and S-1) and four for the other observer (L-4, L-5, S-1), all of them measured less than $5 \mathrm{~mm}$. Right breach pedicles $(26 / 57.77 \%)$ were more common than left $(19 / 42.22 \%)$.

No intraoperative instrumentation-related or postoperative clinical complications were encountered. From the major breached cases $(0.71 \%)$, no one had nerve root injuries or required screw surgical revision.

\begin{tabular}{|c|c|c|c|c|}
\hline & $\begin{array}{l}\text { Observer A } \\
\text { (Screws/\%) }\end{array}$ & $\begin{array}{l}\text { Observer B } \\
\text { (Screws/\%) }\end{array}$ & $\begin{array}{l}\text { Observer C } \\
\text { (Screws/\%) }\end{array}$ & Mean(Screws/\%) \\
\hline No breach & $431 / 91.7$ & $426 / 90.64$ & $425 / 90.43$ & $427.33 / 90.92$ \\
\hline $\begin{array}{l}\text { Minor breach } \\
(\leq 2 \mathrm{~mm})\end{array}$ & $36 / 7.66$ & $40 / 8.51$ & $42 / 8.94$ & 39.33/8.37 \\
\hline $\begin{array}{l}\text { Major breach } \\
(\geq \mathbf{3 m})\end{array}$ & $3 / 0.64$ & $4 / 0.85$ & $3 / 0.64$ & $3.33 / 0.71$ \\
\hline Kappa & Observer & $\begin{array}{r}\text {-B } \kappa=0.769 \\
\text { Observer }\end{array}$ & $\begin{array}{r}\text { bserver B-C } \\
\kappa=0.928 \\
\mathrm{~A}-\mathrm{C} \kappa=0.784\end{array}$ & \\
\hline
\end{tabular}

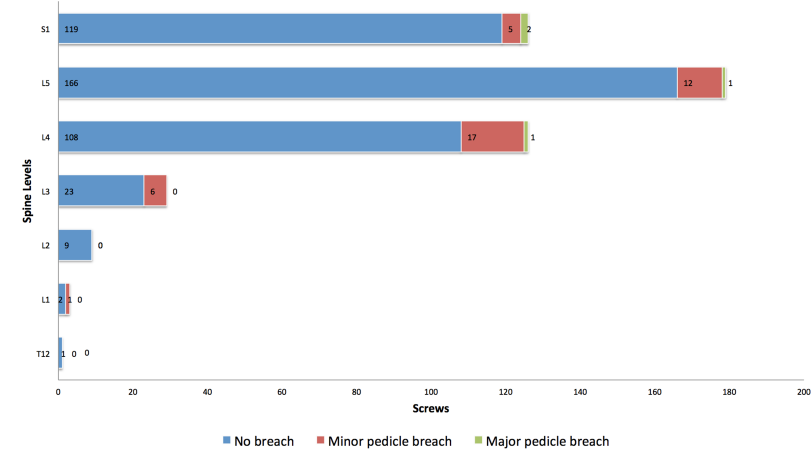

Fig. 3. Stacked bar graphdemonstrating the number of pedicles without pedicle breach, minor pedicle breach and major pedicle breach at each level. 


\section{Discussion}

Although surgical anatomy remains the key factor for pedicle screw placement success, minimally invasive techniques rely on mastering radiological spine anatomy. Our mini-open technique utilizes 2-D fluoroscopy for radiological visualization of the pedicle and the aid of electrophysiological monitoring for the accurate placement of transpedicular screws.

In previous studies, using fluoroscopic guidance in two planes, Castro et al. ${ }^{13}$ reported a pedicle breach of $40 \%$ using open landmarks, however most of them were minor (less than $2 \mathrm{~mm}$ ). Parker et al. ${ }^{10}$ used a free-hand technique with an intraoperative lateral radiography achieving a pedicle breach of only $1.7 \%$. Nevertheless, this percentage is not comparable because this study defined breach as more than $25 \%$ of the screw diameter. MISS techniques under 2-D fluoroscopic guidance had a pedicle breach from $2.38 \%$ to $29.48 \%{ }^{8,1423}$ Malham G.M. et al. ${ }^{14}$ reached $97.5 \%$ pedicle screw accuracy using dynamic EMG and 2-D fluoroscopy; $99 \%$ of 201 screws were found to be within the margins of the pedicle when EMG response was negative to a stimulus $\geq 11 \mathrm{~mA}$. In our results, the pedicle breach rate was $9.08 \%$ of 470 screws using a stimulus intensity of $7 \mathrm{~mA}$ during the Jamshidi needle introduction and $15 \mathrm{~mA}$ while placing the screw. If there was any response to stimulation, screw was placed in a different trajectory. In comparison with navigation-aided pedicle screw placement in which the accuracy is between $92.5-97.3 \%,{ }^{2+29}$ our study had a high radiological accuracy (90.92\%) just below these studies. No clinical complications were encountered, which is similar to the symptomatic breach rate of $0.2 \%$ reported with lumbar percutaneous pedicle screw placement using 3-D stereotactic navigation. ${ }^{30}$ Even though surgeon's radiation exposure and pedicle breach are markedly reduced with 3-D CT or fluoroscopy-navigation methods, they have a significant equipment cost limitation, incapability to get real-time location of guide wires in the vertebral body, radiation exposure to the patient is increased $^{31}$ and clinical outcome benefits have not been definitively demonstrated.

Robot-assisted pedicle screw insertion is a new safe and useful tool for the spine surgeon. ${ }^{32.36}$ A multicen- ter retrospective series found $89.3 \%$ of screws without breach and $9 \%$ with a minor breach using the SpineAssist Surgical Robot. Higher rate of laterally misplaced screws were found in two studies ${ }^{35,36}$ and in one of them, conventional placement had superior accuracy than robot-assisted screws. ${ }^{35}$ The main advantages of the robotic-assisted system are that it does not rely on bony landmarks or camera tracking mechanisms. However, in some cases screw trajectory had to be revised manually and fluoroscopy backup is necessary. ${ }^{36}$

The accuracy of pedicle screw placement using 2-D fluoroscopic guidance relies in radiologic-anatomy correlation. The pedicle is an ellipse with a vertical long axis in the AP projections, the width increases when progressing from $\mathrm{L} 1$ to $\mathrm{S} 1$, becoming an oblique ellipse at L-4 and L-5 and a triangle at S-1. The radiological pedicle is within the true cortical border of the pedicle, which gives a safety cortical pedicle halo for the accurate placement of the screw. ${ }^{37}$ Mastering radiological anatomy of the pedicles is of utmost importance, especially in deformity cases in which the angles and anatomy are modified. S-1 pedicles are not always well observed with fluoroscopy; it is important to localize the medial cortical border, which is the continuation of a trabecular line that forms de sacroiliac joint, and the lateral cortical border, which is always lateral to the $S-1$ foramen. ${ }^{37}$

One of the main disadvantages for our technique is the surgeon's radiation exposure. However the major pedicle breach rate $(0.71 \%)$ was very low because fluoroscopy guidance was used meticulously in every step for the screw placement and neuromonitoring was carefully interpreted. Even though we know the thresholds are variable, the combine use of intensive fluoroscopy with neuromonitoring gives excellent clinical results without complications.

\section{Conclusion}

Our study demonstrated a high accuracy $(90.2 \%)$ for 2-D fluoroscopy-guided pedicle screw using electromonitoring. Only $0.71 \%$ of the 470 screws had a major breach. No clinical complications were documented. Knowing the radiological spine pedicle anatomy and the correct interpretation of EMG are 
the key factors for this technique.

Author contributions to the study and manuscript preparation include the following. Conception and design: Soriano-Sánchez. Acquisition of data: Ortega-Porcayo, Gutiérrez-Partida, Ortíz-Leyva, Ramírez-Barrios. Analysis and interpretation of data: Soriano-Sánchez, Ortega-Porcayo, SánchezEscandón. Drafting the article: Ortega-Porcayo. Critically revising the article: Soriano-Sánchez, OrtegaPorcayo, Gutiérrez-Partida, Ortíz-Leyva, RamírezBarrios, Rodríguez-García, Sánchez Escandón.vReviewed submitted version of manuscript: Soriano-Sánchez, Ortega-Porcayo, GutiérrezPartida, Ortíz-Leyva, Ramírez-Barrios, RodríguezGarcía. Sánchez-Escandón Approved the final version of the manuscript on behalf of all authors: Ortega-Porcayo.

\section{References}

1. Puvanesarajah V, Liauw JA, Lo SF, Lina IA, Witham TF. Techniques and accuracy of thoracolumbar pedicle screw placement. World journal of orthopedics 2014;5:112-23.

2. Kosmopoulos V, Schizas C. Pedicle screw placement accuracy: a meta-analysis. Spine

2007;32:E111-20.

3. Matsuzaki H, Tokuhashi Y, Matsumoto F, Hoshino M, Kiuchi T, Toriyama S. Problems and solutions of pedicle screw plate fixation of lumbar spine. Spine 1990;15:1159-65.

4. Donovan DJ, Polly DW, Jr., Ondra SL. The removal of a transdural pedicle screw placed for thoracolumbar spine fracture. Spine 1996;21:2495-8; discussion 9.

5. Lopera JE, Restrepo CS, Gonzales A, Trimmer $\mathrm{CK}$, Arko F. Aortoiliac vascular injuries after misplacement of fixation screws. The Journal of trauma 2010;69:870-5.

6. Vanichkachorn JS, Vaccaro AR, Cohen MJ, Cotler JM. Potential large vessel injury during thoracolumbar pedicle screw removal. A case report. Spine 1997;22:110-3.

7. O'Brien JR, Krushinski E, Zarro CM, Sciadini M, Gelb D, Ludwig S. Esophageal injury from thoracic pedicle screw placement in a polytrauma patient: a case report and literature review. Journal of orthopaedic trauma 2006;20:431-4.

8. Smith ZA, Sugimoto K, Lawton CD, Fessler RG. Incidence of lumbar spine pedicle breach after percutaneous screw fixation: a radiographic evaluation of 601 screws in 151 patients. Journal of spinal disorders \& techniques 2014;27:358-63.

9. Calancie B, Madsen P, Lebwohl N. Stimulusevoked EMG monitoring during transpedicular lumbosacral spine instrumentation. Initial clinical results. Spine 1994;19:2780-6.

10. Parker SL, McGirt MJ, Farber SH, et al. Accuracy of free-hand pedicle screws in the thoracic and lumbar spine: analysis of 6816 consecutive screws. Neurosurgery 2011;68:170-8; discussion 8 .

11. Toleikis JR, Skelly JP, Carlvin AO, et al. The usefulness of electrical stimulation for assessing pedicle screw placements. Journal of spinal disorders 2000;13:283-9.

12. Landis JR, Koch GG. The measurement of observer agreement for categorical data. Biometrics 1977;33:159-74.

13. Castro WH, Halm H, Jerosch J, Malms J, Steinbeck J, Blasius S. Accuracy of pedicle screw placement in lumbar vertebrae. Spine 1996;21:1320-4. 14. Malham GM, Goss B, Blecher C. Percutaneous Pedicle Screw Accuracy with Dynamic Electromyography: The Early Experience of a Traditionally Open Spine Surgeon. Journal of neurological surgery Part A, Central European neurosurgery 2015;76:303-8. 15. Kim MC, Chung HT, Cho JL, Kim DJ, Chung NS. Factors affecting the accurate placement of percutaneous pedicle screws during minimally invasive transforaminal lumbar interbody fusion. European spine journal : official publication of the European Spine Society, the European Spinal Deformity Society, and the European Section of the Cervical Spine Research Society 2011;20:1635-43.

16. Lau D, Terman SW, Patel R, La Marca F, Park P. Incidence of and risk factors for superior facet violation in minimally invasive versus open pedicle screw placement during transforaminal lumbar interbody fusion: a comparative analysis. Journal of neurosurgery Spine 2013;18:356-61.

17. Luther N, Iorgulescu JB, Geannette C, et al. Comparison of Navigated Versus Non-Navigated Pedicle Screw Placement in 260 Patients and 1434 
Screws: Screw Accuracy, Screw Size, and the Complexity of Surgery. Journal of spinal disorders \& techniques 2013.

18. Nakashima H, Sato K, Ando T, Inoh H, Nakamura $\mathrm{H}$. Comparison of the percutaneous screw placement precision of isocentric $\mathrm{C}$-arm 3-dimensional fluoroscopy-navigated pedicle screw implantation and conventional fluoroscopy method with minimally invasive surgery. Journal of spinal disorders \& techniques 2009;22:468-72.

19. Oh HS, Kim JS, Lee SH, Liu WC, Hong SW. Comparison between the accuracy of percutaneous and open pedicle screw fixations in lumbosacral fusion. The spine journal : official journal of the North American Spine Society 2013;13:1751-7.

20. Raley DA, Mobbs RJ. Retrospective computed tomography scan analysis of percutaneously inserted pedicle screws for posterior transpedicular stabilization of the thoracic and lumbar spine: accuracy and complication rates. Spine 2012;37:1092-100.

21. Ravi B, Zahrai A, Rampersaud R. Clinical accuracy of computer-assisted two-dimensional fluoroscopy for the percutaneous placement of lumbosacral pedicle screws. Spine 2011;36:84-91.

22. Schizas C, Michel J, Kosmopoulos V, Theumann N. Computer tomography assessment of pedicle screw insertion in percutaneous posterior transpedicular stabilization. European spine journal : official publication of the European Spine Society, the European Spinal Deformity Society, and the European Section of the Cervical Spine Research Society 2007;16:613-7.

23. Waschke A, Walter J, Duenisch P, Reichart R, Kalff R, Ewald C. CT-navigation versus fluoroscopyguided placement of pedicle screws at the thoracolumbar spine: single center experience of 4,500 screws. European spine journal : official publication of the European Spine Society, the European Spinal Deformity Society, and the European Section of the Cervical Spine Research Society 2013;22:654-60. 24. Idler C, Rolfe KW, Gorek JE. Accuracy of percutaneous lumbar pedicle screw placement using the oblique or "owl's-eye" view and novel guidance technology. Journal of neurosurgery Spine

2010;13:509-15.

25. Lee $\mathrm{MH}$, Lin $\mathrm{MH}$, Weng $\mathrm{HH}$, et al. Feasibility of Intra-operative Computed Tomography Naviga- tion System for Pedicle Screw Insertion of the Thoraco-lumbar Spine. Journal of spinal disorders \& techniques 2012.

26. Ling JM, Dinesh SK, Pang BC, et al. Routine spinal navigation for thoraco-lumbar pedicle screw insertion using the O-arm three-dimensional imaging system improves placement accuracy. Journal of clinical neuroscience : official journal of the Neurosurgical Society of Australasia 2014;21:493-8.

27. Nottmeier EW, Seemer W, Young PM. Placement of thoracolumbar pedicle screws using threedimensional image guidance: experience in a large patient cohort. Journal of neurosurgery Spine 2009;10:33-9.

28. Oertel MF, Hobart J, Stein M, Schreiber V, Scharbrodt W. Clinical and methodological precision of spinal navigation assisted by $3 \mathrm{D}$ intraoperative $\mathrm{O}$ arm radiographic imaging. Journal of neurosurgery Spine 2011;14:532-6.

29. Scheufler KM, Franke J, Eckardt A, Dohmen H. Accuracy of image-guided pedicle screw placement using intraoperative computed tomography-based navigation with automated referencing. Part II: thoracolumbar spine. Neurosurgery 2011;69:1307-16.

30. Bourgeois AC, Faulkner AR, Bradley YC, et al. Improved Accuracy of Minimally Invasive

Transpedicular Screw Placement in the Lumbar Spine with Three-dimensional Stereotactic Image Guidance: A Comparative Meta-analysis. Journal of spinal disorders \& techniques 2014.

31. Dabaghi Richerand A, Christodoulou E, Li Y, Caird MS, Jong N, Farley FA. Comparison of Effective Dose of Radiation During Pedicle Screw Placement Using Intraoperative Computed Tomography Navigation Versus Fluoroscopy in Children With Spinal Deformities. Journal of pediatric orthopedics 2015.

32. Devito DP, Kaplan L, Dietl R, et al. Clinical acceptance and accuracy assessment of spinal implants guided with SpineAssist surgical robot: retrospective study. Spine 2010;35:2109-15.

33. Kantelhardt SR, Martinez R, Baerwinkel S, Burger R, Giese A, Rohde V. Perioperative course and accuracy of screw positioning in conventional, open robotic-guided and percutaneous roboticguided, pedicle screw placement. European spine journal : official publication of the European Spine 
Society, the European Spinal Deformity Society, and the European Section of the Cervical Spine Research Society 2011;20:860-8.

34. Pechlivanis I, Kiriyanthan G, Engelhardt M, et al. Percutaneous placement of pedicle screws in the lumbar spine using a bone mounted miniature robotic system: first experiences and accuracy of screw placement. Spine 2009;34:392-8.

35. Ringel F, Stuer C, Reinke A, et al. Accuracy of robot-assisted placement of lumbar and sacral pedicle screws: a prospective randomized comparison to conventional freehand screw implantation. Spine 2012;37:E496-501.

36. Schatlo B, Molliqaj G, Cuvinciuc V, Kotowski M, Schaller K, Tessitore E. Safety and accuracy of robot-assisted versus fluoroscopy-guided pedicle screw insertion for degenerative diseases of the lumbar spine: a matched cohort comparison. Journal of neurosurgery Spine 2014;20:636-43.

37. Robertson PA, Stewart NR. The radiologic anatomy of the lumbar and lumbosacral pedicles.
Spine 2000;25:709-15.

\section{Disclosures}

No funding, financial support or industry affiliations were used for this work.

\section{Corresponding author}

Luis Alberto Ortega-Porcayo, Department of Neurosurgery, National Institute of Neurology and Neurosurgery "Manuel Velasco Suárez". Insurgentes Sur 3877. Tlalpan. Mexico City, Mexico. ZC 14269. opalberto@gmail.com.

Published 23 October 2015.

This manuscript is generously published free of charge by ISASS, the International Society for the Advancement of Spine Surgery. Copyright $\odot 2015$ ISASS. To see more or order reprints or permissions, see http://ijssurgery.com. 